\title{
Influence of defects on the very high cycle fatigue behaviour of forged aeronautic titanium alloy
}

\author{
Alexander Nikitin ${ }^{1}$, Thierry Palin-Luc ${ }^{2, a}$, Andrey Shanyavskiy ${ }^{3}$ and Claude Bathias ${ }^{1}$ \\ ${ }^{1}$ LEME, U. Paris Ouest Nanterre La Defense, 50 rue de Sèvres, 92410 Ville-d'Avray, France \\ ${ }^{2}$ Arts et Métiers ParisTech, I2M, CNRS, Université Bordeaux 1, Esplanade des Arts et Métiers, \\ 33405 Talence, France \\ ${ }^{3}$ SCCAFS, Air. Sheremetevo-1, PO Box 54, Moscow reg., Chimkinskiy State 141426, Russia
}

\begin{abstract}
This paper is focused on fatigue failure of forged aeronautic titanium alloy Ti-6Al-4Mo under VHCF loading. Continuous fatigue tests were carried out in gigacycle fatigue regime (up to on $10^{10}$ cycles) on specimens machined from real aircraft compressor disk produced by forging. It has been shown, that crack initiation site shifts from surface to subsurface location with stress amplitude decreasing and fatigue life increasing. Microstructural inhomogeneities so that "hard" alpha particles, borders of large alpha lamella clusters and TiN particles are the cause of fatigue crack nucleation in forged Ti6Al-4Mo titanium alloy under VHCF loading.
\end{abstract}

\section{Introduction}

According to the recent investigations on premature in-service failure of turbo-jet engines, a high frequency vibration could significantly influence the process of fatigue damage accumulation in blades and disks $[1,2]$. It was pointed out that frequency of such loading can reach $1 \mathrm{kHz}$ and more; thus an upper limit in terms of fatigue life for $\mathrm{HCF}\left(10^{6}-10^{7}\right.$ cycles $)$ can be achieved less than in three hours that is significantly less than guaranty in-service time for blades and disks. Therefore during their in-service life, these elements experience more than $10^{9}$ loading cycles that is VHCF range. According to [3] the macroscopic behaviour of a metal in VHCF is elastic except around metallurgical defects, which are typical crack initiation sites in gigacycle fatigue. Therefore, in-service failures of turbine elements should be provoked by defects of material microstructure. Present work is focused on experimental investigation of fatigue crack initiation mechanisms in forged aeronautical titanium alloy under VHCF loading.

\section{Material and experimental conditions}

Alpha - beta forged titanium alloy Ti-6Al-4Mo, used for blades and disks production, was investigated in VHCF range. Hourglass shaped smooth specimens were machined from real compressor turbine-engine

\footnotetext{
${ }^{a}$ Corresponding author: thierry.palin-luc@ensam.eu
}

This is an Open Access article distributed under the terms of the Creative Commons Attribution License 4.0, which permits unrestricted use, distribution, and reproduction in any medium, provided the original work is properly cited. 


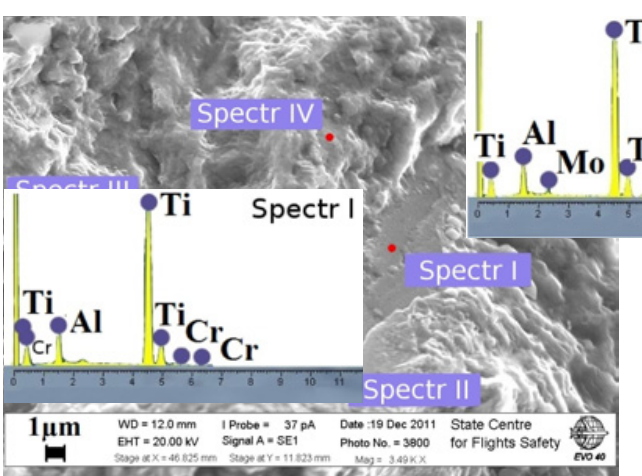

(a)

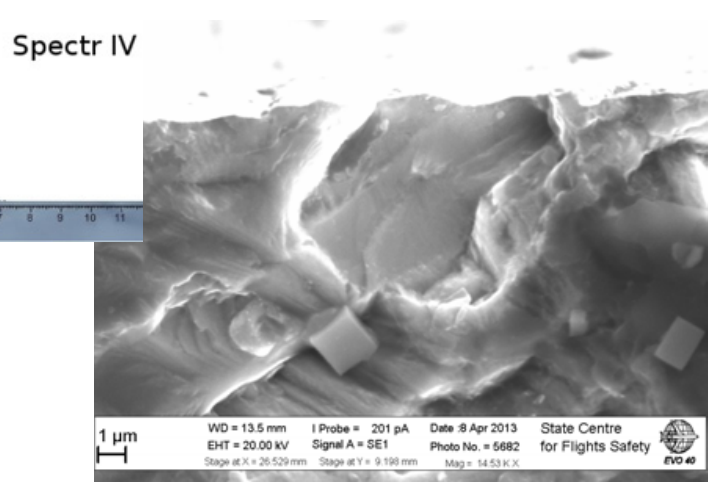

(b)

Figure 1. a) Mo segregation in crack initiation zone, b) extra-hard TiN particules in crack initiation area.

disk. Fully reversed tension and tension - tension $(\mathrm{R}=0.1)$ fatigue tests were carried out at $20 \mathrm{kHz}$ with a piezoelectric fatigue testing machine [4]. Specimens were cooled by dry compressed air flow during all the testing time. Continuous tests were performed until specimen's failure or reaching fatigue life of $10^{10}$ cycles.

\section{Results and discussions}

The fatigue strength of Ti-6Al-4Mo has decrease with increasing the number of loading cycles in $\mathrm{HCF}$ and VHCF. Crack initiation shifts from surface to subsurface for longer fatigue life. Contrarily to steels, forged titanium alloy shows weakly expressed or absent "fish eye" formation on fracture surface. Fatigue crack initiation in VHCF is related to micro-plasticity accumulation around metallurgical or microstructural defects. The analysis of fracture surfaces has shown, that like in some HCF cases [5] crack initiation in VHCF can be provoked by "hard" alpha particles. Another type of crack initiation site is the border of alpha beta lamella clusters. According to [6] a similar mechanism is activated in HCF under stress amplitudes close to the conventionnal "fatigue limit" at room temperature. It was shown that under such loading condition fatigue crack initiation at alpha/beta interfaces becomes dominant over initiations in slip-bands. Furthermore, some micro-segregations of Molybdenum were detected in crack initiation areas, as already reported in [7] but not in VHCF regime. The last type of "non-detectable" defect inherent in this material is extra-hard TiN particle.

\section{Conclusion and prospects}

The analysis of the fracture surfaces of specimens in Ti-6Al-4Mo failed in VHCF regime has shown that fatigue cracks nucleates from microstructural inhomogeneities but do not exhibit so called "fisheyes" like in steels. The crack initiation causes are: "hard" alpha particles, borders of alpha-beta lamella clusters which are typically existing in large forged components and seldom TiN particles. All these features are critical in VHCF regime and should be assumed as defects for components operating under stresses at high frequency.

\section{References}

[1] B.A. Cowles, Int. J. Fracture 80, 147-163 (1996)

[2] R.O. Ritchie, B.L. Boyce, J.P. Campbell and others, Int. J. Fatigue 21, 653-662 (1999) 
[3] C. Bathias, Fatigue limit in metals, Wiley Focus, Hoboken (2014)

[4] C. Bathias, P.C. Paris, Gigacycle fatigue in mechanical practice, Marcel Dekker Ed., New York (2005)

[5] R.K. Nalla, B.L. Boyce, J.P. Campbell, J.O. Peters and R.O. Ritchie, Metallurgical and Materials Transactions 33A, 899-918 (2002)

[6] D.K. Benson, J.C. Grosskeutz and G.G. Shaw, Metallurgical Transactions 3, 1239-1248 (1972)

[7] M.J. Donachie, Titanium: a technical guide, ASM International (2001) 